\title{
13. Project Management and the Australian Bureau of Statistics: Doing What Works
}

\author{
Dennis Trewin, Australian Statistician, Australian Bureau \\ of Statistics
}

\section{Introduction}

Project management has to be a core competency for an organisation like the Australian Bureau of Statistics (ABS) and, indeed, for all our organisations. And I am not just talking about IT projects, I am talking about operational projects, particularly large projects like the population census which we are doing later this year. Now I said IT projects, but that is probably a bad term to use. What we really should be talking about is business projects with IT as an enabler.

I will first go through some of the reasons for needing a project management framework, that is, why the ABS decided to introduce one. I will then walk through the ABS project management framework before talking about some of our key learnings, both successes and failures. Finally I will describe a case study of the application of the project management framework, our Business Statistics Innovation Program.

My key message is the need for an agreed project management framework. This is not only to ensure that you have effective project management, but that it is done in a consistent and effective way. You can then support your project management framework with training programs, guidelines and so forth. If everyone is doing it their own way it becomes much more difficult. I will be talking about the ABS project framework, but I am not trying to sell that to you, what I am trying to sell to you is that it is important to have some form of project framework. And there is off-the-shelf software available. Microsoft Project is one example but there are many others that you might be able to fairly easily adapt for your own particular circumstances.

\section{The ABS Project Management Framework}

Why did the ABS implement a project management framework? There was a situation about eight years ago where we had too many projects running over time and over budget. And there also was a lot of creep in project scope and that's one of the reasons that they were running over time and over budget. Project responsibility was not always clear. There was insufficient ownership by the business areas of projects. There was also insufficient emphasis on 
identifying risks and how they should be managed. And, interestingly, we found there was too much emphasis on output rather than outcomes. This is quite common for projects that are based on new IT applications. There is a tendency to think the job was finished when the IT application had been developed.

Just to give you one example of the emphasis on outputs rather than outcomes, we had a major data warehouse project where the people that developed it said, 'it is built, it meets all the specifications and is fully tested". But the end users were not using it effectively. So the project was not really complete. There was a missing gap between the output of delivering a particular warehouse system and the outcome it being used successfully by the people who should be using it. And I think this is true of a lot of projects. People forget about the last step of assisting users to apply the new system effectively.

And also we did not have a universal approach to project management. A lot of people did take project management seriously but they did it in their own way. We were influenced by a representative of Lend Lease, a company that has a great reputation for project management. In fact they argue that good project management is one of the most significant contributors to their profit margins. At the time they were constructing a new building for us so we had an opportunity to talk to some of their senior people and project management was one of the issues that we talked about.

Our project management framework has seven key elements. These are set out in Table 1. It is not rocket science, but a lot of common sense. But actually having the elements documented and used to manage projects is very sensible.

\section{TABLE I: Key Elements of the Project Management Framework}

- $\quad$ Project Planning

- Management of Risk

- Management of Issues

- Management of Change

- Project Quality

- Project Governance

- Project Financial Management

The first phase I will talk about is project planning. This phase sets out the business case including the specification of outcomes that you actually want to achieve. But also, importantly, it defines measures that determine whether you actually met these outcomes or not. It also sets out the project outputs and how they are linked to the project outcomes.

Management of risk is extremely important. The first step is to identify what the significant risks are and this really should be done in a brainstorming type 
of session. And sometimes it is very useful to bring in people who are not too closely associated with the project. You might bring in people who may not know much about the particular project but they have experience in project management and through this set of eyes they can see things that often those that are closer to the project cannot see. After you have identified the risk it is important to develop risk mitigation strategies, i.e. how might you reduce or even eliminate a risk. And then you have to make a decision on whether you will adopt the risk mitigation strategy or take the risk. In some cases its impact may be so low or the chance so low you decide, well let us take the risk and not expend the resources involved in reducing the risk. It is also an important part of project management to think about what the contingency plans will be where you are not fully taking account of a risk. And of course it is important to monitor risks all the way through the project. They can change.

We all know from our experience that issues crop up all the time. They need to be managed but it does not make sense to deal with them one by one as they occur. It would simply lead to chaos. I guess some are so important you have to and that is where judgement comes to play. But all issues should be recorded and it is important to examine if there are some patterns emerging so that you can address issues in a systemic way rather than just on a one by one ad-hoc way. And as issues are processed they become either tasks or risks or dropped as no longer an issue because they are not sufficiently important.

Management of change is another key part of project management. And this should be planned for early in the project rather than waiting until the commissioning stage, because it really can be the key to success. We all know that change is not always welcome by those who are most affected. A lot of people prefer to live in their comfort zone. So it is important to identify the people who might be affected by change, understand what their concerns are and develop plans to address these concerns. It is also important to win their hearts and minds and that they know and understand why you are making change. You need to convince people that it is not only in the long term interest of the organisation that it is also in their long term interest if that is the case. If it is not their long-term interest it is better that they know that sooner rather than later as well. It helps them plan their future. Job design is a very important part of this process. And if you can, you should allow the people who are most affected to influence the way jobs are designed. And training or reskilling of course is a vitally important part of the management of change, particularly if staff are changing responsibilities.

Project quality is largely common sense. For your outputs, determine how you are going to decide whether they are actually fit for purpose. What are the measures of success? 
Project governance is important. Many projects fail because the governance arrangements are inappropriate or unclear. First of all, establish milestones and manageable project phases. A lot of projects are very big so it is important to break them down into chunks, manageable chunks. We have a rule that we do not allow any project phase to last more than 12 months or take up more than four staff years. Once you get beyond that, it is starting to get difficult to manage. Of course lots of large projects are much bigger than that. So you should try and break it down into manageable chunks that you can control much more easily, as well as being able to gain a full understanding of the links between the different chunks. These have to be managed as well.

As to setting up the actual governance arrangements, this is 'horses for courses'. Our project management framework suggests that a project board be set up. And generally you should make the business area provide the chair of the project board just to make sure the project ownership is appropriate and senior people from the business area are involved throughout the project. For smaller projects this might be overkill and the usual line manager, if you like, can take on the responsibility of the project board, i.e. the decision making responsibility: determining key strategies, monitoring project progress and so forth. But they may decide to set up a consultative or steering group to assist them even though they are taking the main responsibility. But no matter what the project governance arrangements are it is important to define and document the roles and responsibilities of all who are involved or confusion can reign. People can start getting involved in activities that are not really their business. Or the reverse can occur, that is they do not take responsibility for things that they really should be responsible for. The key role is the project manager. That is the person who has most responsibility for the things that happen from day to day. And the project owner is important. They often are the Chair of the Project Board or they may delegate their authority to someone else. But they must retain ownership.

It is necessary to make hard decisions that may change original project plans if things do not proceed according to plan. It may be that as things develop the original plan does not make sense anymore, that you should do something somewhat different. You may have budget blowouts or time table blowouts perhaps even in the early phases of the project. And making necessary adjustments to the project plan is a very important plan of the responsibility of the project board or whatever governance arrangements you establish. We try very hard to maintain budgets and timetables no matter what. So, if things are not going according to plan the preferred option is to modify our ambitions rather than just let things slip.

I will not say much about the project financial management except that it is largely common sense. We have found it useful to analyse variations to 
expenditure plans, particularly significant variations, because it can give you insights into potential problems.

Within our project management framework, there is a set of facilities that are part of the framework. First of all there is a software package. We have developed our own package within the Lotus Notes system. To support the package there are a range of templates (e.g. Issues Management, Risk Management) and Guidelines. And there are also support arrangements inside the ABS, experts on project management that people can talk to particularly in the early stages of a project but also in the intermediate and later stages if problems emerge. We have also contracted an external expert, a chap by the name of John Smyrk who helps us from time to time, particularly in the early stages of large projects. And the suite of tools is supported by classroom training and an online training package.

Just repeating something I said at the start of the talk, I am not arguing that you should use the ABS project management framework, I am just using it as an illustration of a framework and suggesting that something along these lines is important for all organisations. It is also important for all projects whether IT enabled or not.

\section{What have we learnt from the use of the Project Management Framework?}

I will first turn to a summary of the successes we have had since the introduction of the Project Management Framework. Since we introduced the project management framework we have experienced better control of projects. We have managed risks much better. For each project we go through a process of identifying risks and working out how they should be controlled. Problems have been identified earlier and therefore much easier to resolve. Also our financial performance on projects has been much better. There have been less budget blow outs. Quality has been built into project outputs - there has been greater collaboration between the project team and the project owners on what fit for purpose actually means. And that is partly because of the improved information flow between the different stakeholders and a better understanding of their respective roles. So we have reduced project creep. Project creep now is seen in a negative light and avoided. If there really is a need to add functionality to a particular project it is seen as a separate exercise, requiring separate justification.

There are some lessons we have learnt, particularly from our early experiences. The first one is getting the scale of project management in proportion to the size and impact of a project. The mistake we made was using the project management framework to its full extent on every project and for some projects that was a sledgehammer cracking a nut. So adapting the project management framework to fit the particular characteristics of a project is quite important. We've also 
learnt to monitor milestones better. And to take deliberate action once we realised that a milestone will not be met rather than just hoping that you'll catch up at some later stage in the project.

Some of the projects board got into micro-managing the project. The micro-management tasks are for the project manager and his/her team, not the board. So having a clear understanding of the respective roles of the project board and the project manager is something that has been refined with experience. And the other lesson is to kill-off projects or significantly modify projects if it is clear that they will not deliver. This is a very important role for the project board. Project managers can often fall in love with what they are doing and it is very hard for them to let go. But project boards are a step removed and should be in a position to stop projects if that is what is really necessary. It is not easy to admit failure.

\section{A Case Study - The Business Statistics Innovation Program}

Now I am now moving onto the case study. It is our Business Statistics Innovation Program (BSIP). It finished in June 2005. It was aimed at achieving multiple outcomes as described in Table 2 .

TABLE 2: Outcomes Sought from the Business Statistics Innovation Program

- Improved efficiency/productivity

- Methodological and technological improvement (exploiting new data sources (e.g. taxation) and new technologies e.g. input data warehouses)

- Improved data quality

- Improved management of business respondents

- Increased capacity to respond to emerging needs

- Stronger statistical leadership

- Enhanced opportunities for staff

I will soon tell you a little bit about what we actually achieved through this project. What we were trying to do was adapt new technology and new methodologies to achieve desirable business outcomes. But to be successful we also had to move away from an organisational structure that was based largely on silos. ABS collection activities were largely vertically organised around particular statistical collections or groups of collections and that stopped us getting full advantage of new technologies, new methodologies where economies of scales matter as well as reducing the coherence of statistics across the silos. The following diagram illustrates what we did (Figure 1): 


\section{Figure 1}

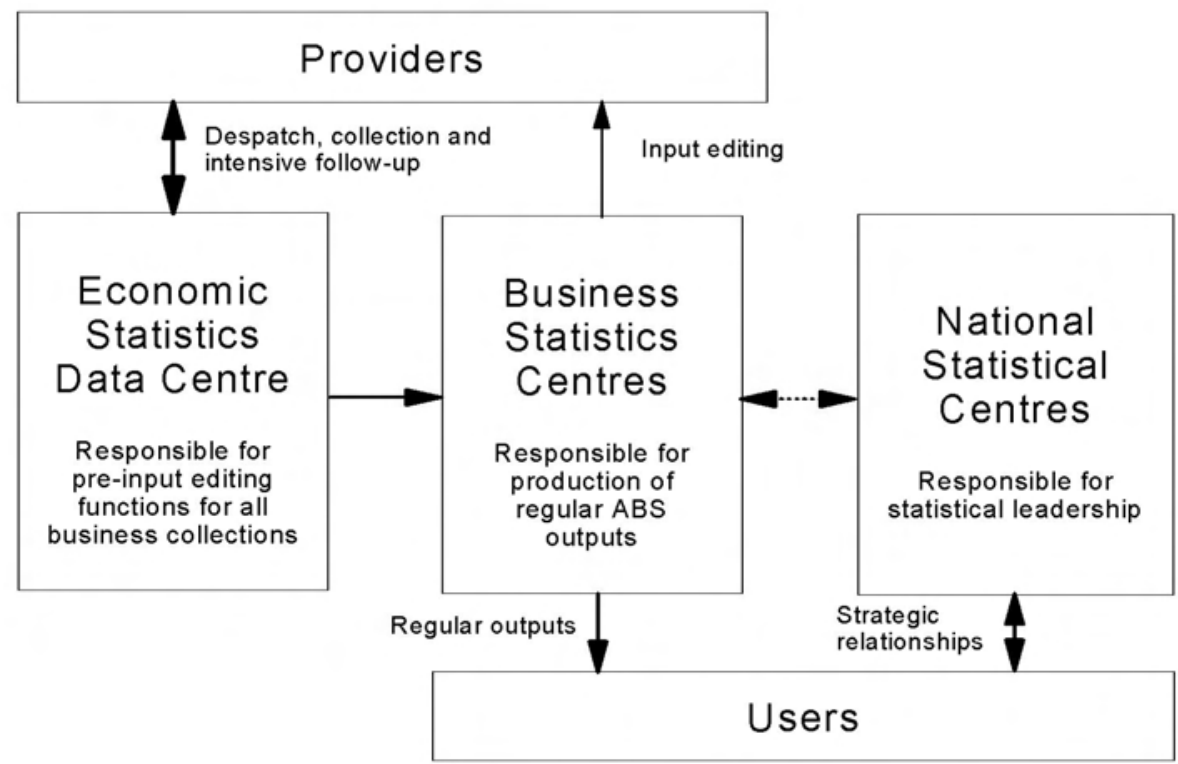

We changed from a vertically structured organisation that I just talked about to a more horizontal structure to provide greater functional specialisation and economies of scale. Starting on the left hand side of the diagram, we have the Economic Statistics Data Centre which undertakes all the data collection activities, all the front end processing activities and so forth. There is only a single data centre whereas there are multiple Business Statistic Centres (BSCs), shown in the middle part of the diagram. They are based around groups of similar business collections. For example we have one Business Statistic Centre (BSC) for all our sub-annual business collections, we have another BSC for all our agriculture collections. The third type of organisational unit is the National Statistic Centres (NSCs). There are multiple National Statistic Centres and they are based on particular statistics themes. So we have a labour NSC, for example, and its role is to get away from being solely based on internally focused labour collection based activity that it was responsible for to having a much greater alignment with the users and producers of labour statistics and to take an interest in all data sources that could be used for labour statistics.

BSIP was a significant program, taking a bit over three years to establish. But we went about it in a structured way. Firstly we consulted very broadly with staff, very early when we were first thinking of making changes. And we actually changed plans as a result of those consultations. I personally got involved in some of the consultations because I wanted to demonstrate my own interest in this major change program as well as hearing first hand the reactions of staff. 
As I mentioned above, we exploited the available technology. It was new technology, but not leading edge.

A key objective of this whole program was to exploit new administrative data sources. The key source we had was taxation data and with the introduction of the GST all of a sudden we had available to us all the information on the business activity statements. So in effect we were getting a business Census every quarter. People may not have liked GST but statisticians did because they had this wonderful new data source that they could now use to produce new statistics or reduce the collection load we place on businesses. And BSIP was also an opportunity to introduce greater consistency across our statistical collections. They each had their own life and developed the way they did things independently. This may have been justified when looked at in isolation but they were different so we didn't have the degree of coherence that we would have liked across our statistical sources. Re-skilling staff was an important part of the 'how' and very early in the change program we identified the training needs. And consistent with the theme of this chapter, good project management was also very important.

I would now like to make a few more detailed comments on the involvement of staff. Before we actually started the program we developed a set of what we call strategic scenarios and they were the basis of the discussions we had with staff and unions. The key thing was not only that we did talk to staff about the scenarios but we weren't just lecturing, we were also listening. We actually made changes as a result of the feedback and that helped get greater ownership of what we were doing. Once BSIP was broken down into specific projects we also provided scope for staff to have an influence on exactly what was going to happen within each project, particularly on job design aspects. And there was continuous commitment from senior staff for the whole program. The end result was that, in terms of staff reaction, we moved from staff being very sceptical at first (understandably because there was concern about things like job tenure, what sort of work they were going to be doing, whether they were going to be made redundant, would they have the skills to do it) to reluctant commitment. By the end of the three years we really had most staff very committed and enthusiastic about the whole program and looking for ways to actually do new things that we hadn't actually thought of.

With respect to governance, we set up a BSIP management board. I will mention one thing that I think is quite important: we included an outside expert on the program management board. We thought it was important to have someone who was going to have a different perspective and that actually proved to be very useful. We also as I mentioned before used a chap named John Smyrk who did a review at the very beginning of the proposed arrangements and also mid way through the program just to give us some insights on some things that we might 
do a little bit better. The BSIP program was broken up into a series of projects and line managers took responsibilities for particular projects. Because of the size of BSIP we set up an implementation coordination team that provided secretariat and monitoring services and a range of other support activities.

In terms of achievements, I guess the one that we are most pleased about was that we more than achieved our productivity goals. We were planning to reduce from 1,029 staff employed on business statistics to 895 in fact we ended up with 856. And other good things happened whilst BSIP costs stayed within budget. The organisational change was completed but business continuity was important. In the early phases of the project we managers asked about measures of success and business continuity was at the top of the list. We did not want to implement the changes in a way that meant that particular statistics were going to be delayed or not produced for a particular period of time, or that there were serious discontinuities in time series. We managed to do this and being able to achieve this goal was very important to the success of the project.

There were a number of lessons learnt. First of all, the need to be clear and focused at the start about the outcomes being sought. A lot of the projects fail because the outcomes or goals that were being sought were not clear. This was a big program, involving a massive change. We had a number of projects that contributed to the program but they all needed to be inter-related. So having all that set out clearly and setting up the governance arrangements to allow it to happen and manage issues is important.

Keeping the amount of change manageable is another lesson. We actually cut back on some of our plans when we thought that it was going to be too much to achieve at one time. Communication is very important. We used our intranet to get messages, particularly from me, out to staff about what was happening and how progress was made. But there is nothing like face-to-face communication and we encourage the senior people who were involved in BSIP to get out and about as much as they could and let people know what was happening. This is a three-year program, and staff do not want to hear 'nothing' about it for those three years. People want to actually know what is happening as the project progresses. And just repeating what I said a few moments ago, address the skills development process early in the program. It is very important to involve staff in working out exactly what the skill gaps are and what you might do to address them. It also helps develop ownership. 